\title{
Emotional Intelligence and Its Relationship to Stress and Transition Shock Amongst First-Year College Students
}

\author{
Nathaniel S. Thomas ${ }^{1}$, Chaeryong Pak ${ }^{1}$, Kenneth Lalog ${ }^{1}$, Beryl Ben C. Mergal ${ }^{2}$ \\ ${ }^{1}$ Nursing Student, Adventist University of the Philippines \\ ${ }^{2}$ Research Consultant, Adventist University of the Philippines \\ bbcmergal@aup.edu.ph
}

\begin{abstract}
Freshmen students often experience transition shock as their environment change from high school to college. They are also under the impression that success in college depends solely on their intellect and usually do not consider emotional intelligence a factor into the success of their academic endeavors. The purpose of this study was to investigate emotional intelligence and its relationship to stress and transition shock amongst first-year college students. A descriptive-correlational research design was employed. One hundred nineteen respondents were chosen using purposive sampling technique. Frequency, percentage distribution, weighted mean, standard deviation, and Pearson $\mathrm{r}$ correlation coefficient test were used to analyze and treat the collected data. Respondents showed a high emotional intelligence having an overall mean of $2.73(\mathrm{SD}=0.35)$. The extent of the respondents' stress was also high with an overall mean of $2.61(\mathrm{SD}=0.59)$. As for the extent of transition shock felt by the respondents, the overall mean found is at 2.55 ( $\mathrm{SD}=0.52$ ) which is also interpreted as high. A moderate negative significant relationship between emotional intelligence and stress $(r=-0.476)$, as well as the relationship between emotional intelligence and transition shock $(\mathrm{r}=-0.417)$ among the freshmen. It is recommended that nursing students and educators become aware of emotional intelligence as a factor that contributes to the success of the students' transition from high school to college. Also, it is emphasized to further develop the emotional intelligence of the students to manage their stress and transition shock to aid in the success of the students' academic endeavors.
\end{abstract}

Keywords: Nursing, Emotional Intelligence, Transition Shock, Stress

\section{INTRODUCTION}

Adapting to a new environment has always been a challenge, even more so when everything an individual has known is left behind. This is said to be true when a new high-school graduate thrusts into their first year in college. Nakalema and Ssenyonga (2014) explain that due to high expectations, information overload, academic pressure, impractical ambitions, limited prospects, and high competitiveness, academic stress weighs down on the students, 
making the adjustment into their new academic environment difficult. Tinto (as cited in Watson \& Watson, 2016) stated that the first year in college is a difficult and imperative transitional period that can be attributed to either the students' academic success or failure.

The purpose of this study was to determine the relationship of EI to stress and transition shock among first-year college students. This study answered the following research questions:

1. What is the extent of the emotional intelligence of the respondents?

2. What is the extent of the stress of the respondents?

3. What is the extent of transition shock among the respondents?

4. Is there a significant relationship between emotional intelligence and stress among the respondents?

5. Is there a significant relationship between emotional intelligence and transition shock among the respondents?

\section{LITERATURE REVIEW}

A study done by Holinka (2015) at the University of Connecticut explored EI and stress and their relation to a student's life satisfaction. Findings revealed that the students' level of EI does not affect the students' stress level. This study confirmed the results of the study by Watson and Watson (2016), stating that EI also does not affect the students' stress level. On the contrary, a more recent investigation done by Bowen, Pilkington, and Rose (2016) revealed that there was a positive correlation between EI and perceived stress. Moreover, the study posited that academic employees with high EI were able to manage stress better than those with low EI. In another study done by Kauts (2016), it found that students with high Emotional Intelligence experienced lower academic stress.

On the other hand, transition shock is commonly associated with the experience that newly graduated nurse feels among themselves when they are adjusting to their new working environment (Duchscher, as cited in University of Tasmania, 2014). The same feeling could also be experienced by first-year college students. They are faced with new challenges, goals, and responsibilities and struggles to adapt to their new environment. Both the nurse and the first-year college student strive to survive in the situations they are faced with.

As a result of the stress and transition shock that these first-year college students experience, they begin to feel the burden of being in college. In the survey done by the National Alliance on Mental Illnesses (2012), it was revealed that almost two-thirds (64\%) of the students 
dropped out of college due to mental health reasons. The American Psychological Association (2017) also stated that the common concerns reported by the college students seeking counseling were anxiety (61\%), depression (49\%), stress (45\%), and academic performance (28\%). The study conducted by American freshman in 2014 by the University of California-Los Angeles, showed that the students who began college entered with just $50.7 \%$ reporting above-average emotional health; the lowest-ever level of emotional health. In the Philippines, there is about $89 \%$ dropout rate which means that the country produces 2.13 million college dropouts annually (Manila Bulletin, as cited in Orion, Forosuelo \& Cavalida, 2014).

Though studies have been done to explore the relationship between students' emotional intelligence (EI) and stress, there is a dearth in the literature correlating EI to transition shock. Currently, there is a dearth of literature correlating EI to stress among first-year college students. Furthermore, no studies have been conducted to correlate EI and transition shock. Thus, this study was conducted. This study looked into the relationship between the EI and the stresses experienced by first-year college students. This study also investigated the relationship of emotional intelligence to the transition shock felt by the first-year college students.

\section{METHODS}

This study utilized the descriptive-evaluative design to determine the emotional intelligence, level of stress and level of transition shock of the respondents. The study also used the descriptive-comparative research design, in which the extent of the variables was compared according to their age, gender, ethnicity and family income. Also, it compared the effect of the emotional intelligence of an individual on the stress level and transition shock level. The study first observed a difference that exists within a group of people and then looked back in time to determine possible conditions that might have resulted in this observed difference (Mertler, 2014). Lastly, the study used a descriptive-correlational design to determine the relationship between emotional intelligence to level of stress and the relationship of emotional intelligence to transition shock among the respondentsCorrelational studies do not test the casual relationship but rather test the extent of the relationship between variables.

The target population for this study was the first-year college students who are staying incampus. A purposive sampling technique had been utilized to select the respondents who met the following criteria: The first-year college students who were enrolled during the inter- 
semester of 2018, stayed in-campus, 16-22 years old, could read and understand English, and were willing to participate First year college students that are more than 22 years, staying with parents or living off-campus, taking second courses, married or with small children, and from the college of medicine, are all excluded from the study.

The instrument that has been used in the study is the questionnaire-checklist, which is composed of three parts namely:

1. The first part includes a demographic profile to collect the information on the respondents such as age, sex, ethnicity, and family income.

2. The second part of the questionnaire assesses the dimension of emotional intelligence. The questionnaire was adapted from the Trait Emotional Intelligence QuestionnaireShort Form (TEIQue-SF). The test is predicated on trait EI theory, which conceptualizes emotional intelligence as a personality trait, located at the lower levels of personality hierarchies (Petrides, Pita \& Kokkinaki, 2007). The TEIQue- SF consists of 30-items including two items from each of the 15 facets of the TEIQue. Whereas global trait EI is the average score of all 30 items, the four subscale scores are derived from 26 of these items: Well-Being, Self-Control, Emotionality, and Sociability (Petrides\& Furnham, 2006). The statements ask the emotion-related aspects of the personality of the respondents.

3. The third part of the questionnaire measured the individual's stress levels. The questionnaire had been adapted from the Perceived Stress Scale (PSS) which was originally developed in 1983 that remains to help understand how different situations affect people's feelings and their perceived stress. It includes ten questions that ask about the feelings and thoughts that the respondents have experienced in the last month. For each question, the frequency of thoughts and feelings was asked to be indicated.

To interpret the results and findings, a Likert-type scale with its verbal interpretation had been used. A four-point Likert scale and the degree of intensity together with the verbal interpretation are explained in Tables 1, 2 and 3 below. 
Table 1. EI Assessment Criteria

\begin{tabular}{cccc}
\hline \multicolumn{2}{c}{ LIKERT SCALE } & $\begin{array}{c}\text { Verbal } \\
\text { Interpretation }\end{array}$ & $\begin{array}{c}\text { Weighted Mean } \\
\text { Interval }\end{array}$ \\
\hline 4 & Degree of Intensity & Very High & $3.50-4.00$ \\
3 & Strongly Agree & High & $2.50-3.49$ \\
2 & Agree & Low & $1.50-2.49$ \\
1 & Disagree & Very Low & $1.00-1.49$ \\
\hline
\end{tabular}

Table 2. Extend of Stress Assessment Criteria

\begin{tabular}{cccc}
\hline \multicolumn{2}{c}{ LIKERT SCALE } & $\begin{array}{c}\text { Verbal } \\
\text { Interpretation }\end{array}$ & $\begin{array}{c}\text { Weighted Mean } \\
\text { Interval }\end{array}$ \\
\hline 4 & Degree of Intensity & Very High & $3.50-4.00$ \\
3 & Always & High & $2.50-3.49$ \\
2 & Often & Low & $1.50-2.49$ \\
1 & Sometimes & Very Low & $1.00-1.49$ \\
\hline
\end{tabular}

Table 3. Transition Shock Assessment Criteria

\begin{tabular}{|c|c|c|c|}
\hline \multicolumn{2}{|c|}{$\underline{\text { LIKERT SCALE }}$} & \multirow{2}{*}{$\begin{array}{c}\text { Verbal } \\
\text { Interpretation }\end{array}$} & \multirow{2}{*}{$\begin{array}{c}\text { Weighted Mean } \\
\text { Interval }\end{array}$} \\
\hline Response Scale & Degree of Intensity & & \\
\hline 4 & Strongly Agree & Very High & $3.50-4.00$ \\
\hline 3 & Agree & High & $2.50-3.49$ \\
\hline 2 & Disagree & Low & $1.50-2.49$ \\
\hline 1 & Strongly Disagree & Very Low & $1.00-1.49$ \\
\hline
\end{tabular}

This study was subjected to Ethics Review by the Ethics Review Board (ERB) of the Adventist University of the Philippines. The ERB then issued a certification to conduct the study. As part of the ethical consideration of the study, informed consent was secured from the respondents to voluntarily participate in the study. Before the study was conducted, a complete explanation of the purpose and nature of the study had been given to the respondents. A verbal consent had also been given to the respondents, indicating that all data 
collected will be kept with confidentiality, specifically by removing the names of the respondents. Confidentiality in dealing with the data that was gathered was also observed.

\section{RESULTS AND DISCUSSION}

The Extent of Emotional Intelligence

Table 4 shows the perceived extent of the first-year college students' emotional intelligence and the analysis and interpretation of the results. It presents that the majority of the respondents "generally believe that things will work out fine in their life", with a mean of $3.26(S D=.6946)$. It is followed by the responses of the respondents that they "feel that they have a number of good qualities" giving the mean of $3.19(S D=.7281)$. The third highest item is "generally, I'm able to adapt to new environments", having a mean of 3.08( $S D=$ .8198). These items were all interpreted as high.

However, the item that ranked lowest has a mean of $2.10(S D=.7961)$ stating "I tend to change my mind frequently". The second to the lowest in rank is "I tend to get involved in things I later wish I could get out of", with a mean of 2.24( $S D=.8127)$. The item that ranks third to the lowest states "many times, I can't figure out what emotion I'm feeling" and presents the mean of 2.26(SD $=.8969)$. These are all interpreted as low.

The over-all mean score of emotional intelligence of the respondents is $2.73(S D=.3505)$ and is interpreted as high.

Table 4. The Extent of Emotional Intelligence of the Respondents

\begin{tabular}{|c|c|c|c|c|c|}
\hline Item No. & Emotional Intelligence & WM & SD & VR & VI \\
\hline 2. & $\begin{array}{l}\text { I generally believe that things will work } \\
\text { out fine in my life. }\end{array}$ & 3.26 & .6946 & Agree & High \\
\hline 3. & $\begin{array}{l}\text { I feel that I have a number of good } \\
\text { qualities. }\end{array}$ & 3.19 & .7281 & Agree & High \\
\hline 29 & $\begin{array}{l}\text { Generally, I'm able to adapt to new } \\
\text { environments. }\end{array}$ & 3.08 & .7544 & Agree & High \\
\hline 6. & I generally don't find life enjoyable. & 3.08 & .9350 & Agree & High \\
\hline 1. & On the whole, I'm pleased with my life. & 3.08 & .7720 & Agree & High \\
\hline 18 & I often pause and think about my feelings. & 3.06 & .7951 & Agree & High \\
\hline 20 & I can deal with people effectively. & 3.01 & .7865 & Agree & High \\
\hline 10. & $\begin{array}{l}\text { I'm usually able to find ways to control } \\
\text { my emotions when I want to. }\end{array}$ & 3.00 & .8025 & Agree & High \\
\hline 4. & I believe I'm full of personal strengths. & 2.98 & .7477 & Agree & High \\
\hline 11. & On the whole, I'm able to deal with stress. & 2.98 & .7700 & Agree & High \\
\hline
\end{tabular}


21 I would describe myself as a good negotiator.

19 Those close to me often complain that I don't treat them right.

30 On the whole, I'm a highly motivated person.

12 Others admire me for being relaxed.

13 Expressing my emotions with words is not a problem for me.

16 I often find it difficult to see things from another person's viewpoint.

28 I find it difficult to bond well even with those close to me.

22 I often find it difficult to stand up for my rights.

15 I often find it difficult to show my affection to those close to me.

26 I often find it difficult to adjust my life according to the circumstances.

25 I don't seem to have any power at all over other people's feelings.

7. I usually find it difficult to regulate my emotions.

27 I normally find it difficult to keep myself motivated.

23 I tend to "back down" even if I know I'm right.

17 Many times, I can't figure out what emotion I'm feeling.

8. I tend to get involved in things I later wish I could get out of.

9. I tend to change my mind frequently.

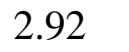

.7497

Agree

High

.9387

Agree

High

2.8

.8198

Agree

High

2.78

2.76

2.73

$$
.8147
$$

Agree

High

.9385

Agree

High

2.67

$$
2.57
$$

.7778 Agree High

$\begin{array}{llll}.67 & .9030 & \text { Agree } & \text { High }\end{array}$

$\begin{array}{llll}2.57 & .8789 & \text { Agree } & \text { High }\end{array}$

$\begin{array}{llll}.50 & 9286 \text { Disagr Low }\end{array}$

$2.45 \quad .7784$

ee

Low

$2.40 \quad .8048$

Disagr

ee

ee

$\begin{array}{lll}2.34 & .8952 \quad \text { Disagr }\end{array}$

ee

$2.34 \quad .8856$

Disagr

ee

2.26

.8969

Disagr

ee

$2.24 \quad .8127$

Disagr

ee

$2.10 \quad .7961$

Disagr

Low

ee

$\mathbf{2 . 7 3} \quad \mathbf{3 5 0 5}$ Agree

High

Legend: $1.00-1.49=$ strongly disagree $; 1.50-2.49=$ disagree $; 2.50-3.49=$ agree $; 3.50-4.00=$ strongly agree

WM-Weighted Mean; SD-Standard Deviation; VR: Verbal Response; VI-Verbal Interpretation.

According to Petrides (2013), people with high EI own a perceived capacity to understand, process, and use information about their and other people's emotions in their everyday life. The findings showed that the majority of the freshman students can monitor own and other people's emotions, to discriminate between different emotions and label them appropriately and to use emotional information to guide thinking and behavior. Also, the EI score reflects 
that they have abilities to join intelligence, empathy, and emotions to enhance thought and understanding of interpersonal dynamics.

People with high scores on EI can recognize and express feelings and utilize these characteristics to develop and maintain close relationships with significant others. Also, they have a strong level of controlling their urges and wants and can adjust to external pressures and stress (Petrides as cited in Andrei, Smith, Surcinelli, Baldaro, \& Saklofske, 2015).

Andrei et al. (2015) also described that EI also includes sociability factor, which indicates that higher EI better the social interactions they have in society. They can communicate and express themselves clearly and confidently, which closely links with leadership as well.

The Extent of Stress of the Respondents

As inferred from Table 5, the item which ranked highest has a mean of $2.92(S D=.819$.), the question states "How often have you felt nervous and stressed?" and is interpreted as high. The second highest item states, "How often have you felt that you were unable to control the important things in your life?", is interpreted as high and has a mean of $2.65(S D=.829)$.

On the contrary, the item which ranks second to the lowest states, "How often have you felt difficulties were piling up so high that you could not overcome them?", has a mean score of $2.45(S D=.861)$ and is interpreted as low. The item which had the lowest mean of $2.43(S D=$ .94) states "How often have you found that you could not cope with all the things you had to do?", is also interpreted only as low.

Lastly, the table also indicates that the overall mean of the perceived stress level of the respondents has a mean of $2.61(S D=.5913)$ which is interpreted as high.

Table 5. The Extent of Stress of the Respondents

\begin{tabular}{clcccc}
\hline $\begin{array}{c}\text { Item } \\
\text { No. }\end{array}$ & \multicolumn{1}{c}{ Perceived Stress } & WM & SD & VR & VI \\
\hline 3 & $\begin{array}{l}\text { How often have you felt nervous and } \\
\text { stressed? }\end{array}$ & 2.92 & .819 & Often & High \\
2 & $\begin{array}{l}\text { How often have you felt that you } \\
\text { were unable to control the important } \\
\text { things in your life? }\end{array}$ & 2.65 & .829 & Often & High \\
$1 \quad \begin{array}{l}\text { How often have you been upset } \\
\text { because of something that happened } \\
\text { unexpectedly? }\end{array}$ & 2.61 & .805 & Often & High \\
$9 \quad \begin{array}{l}\text { How often have you been angered } \\
\text { because of things that happened }\end{array}$ & 2.59 & .858 & Often & High
\end{tabular}


outside of your control?

10 How often have you felt difficulties

$.861 \quad$ Sometimes Low were piling up so high that you could not overcome them?

6 How often have you found that you .720 Sometimes

Low could not cope with all the things that you had to do?

\section{Overall Perceived Stress Level}

\subsection{1}

0.5913

Often

High

Legend: $1.00-1.49=$ Never $; 1.50-2.49=$ Sometimes $; 2.50-3.49=$ Often $; 3.50-4.00=$ Always WM-Weighted Mean; SD-Standard Deviation; VR: Verbal Response; VI-Verbal Interpretation.

The results of the study showed that the respondents often feel stressed and nervous during their first year in college. This is expected from incoming students who are still trying to cope with their new responsibilities, academic requirements, and overall living environment. All these things bring about stresses and nervousness to the students. First-year students often feel stresses, loneliness, and the new responsibilities they undertake may at times overwhelm them (Bhujade, 2017).

The respondents also seem to feel that they are unable to control important aspects of their lives. A survey conducted by the Jed Foundation (2015) reported that about $51 \%$ of the firstyear students surveyed felt stressed most of the time and $36 \%$ felt like they did not have control over things in their lives; the results of the survey corresponds to the findings of the study. This indicates that the respondents may have different decisions made for them, perhaps by their guardians or parents. This makes them feel that they have no independence or control over the things they would like to do in life. Overall, the results of this study show that the respondents often feel stressed in their day to day lives.

\section{The Extent of Transition Shock of the Respondents}

Table 6 shows that the item that ranks the highest is "I miss my parents". This item has a mean of $3.51(S D=.72)$ and is interpreted as very high. The item that ranks second is the item that states "I miss my family members", with a mean of $3.44(S D=.7880)$, interpreted as high. The third highest item is the item "I miss my friends from high-school" with a mean of $3.40(S D=.73 .90)$ and is also interpreted as high.

The table also reflects items that rank lowest in mean scores. The lowest item found in the table is the item "I think about dropping out" with a mean of $1.61(S D=.9123)$, interpreted as low. The second lowest item is "I don't like my course" which has a mean score of 1.89 (SD $=.1 .0151)$ and is interpreted as low. And lastly, the item with the third lowest mean score of 
$2.03(S D=.1 .0246)$ and interpreted as low, "I feel like my absences have increased since I got to college".

The overall transition shock level of the respondents has a mean score of $2.55(S D=.5230)$ which is interpreted as high.

Table 6. The Extent of Transition Shock of the Respondents

\begin{tabular}{|c|c|c|c|c|c|}
\hline $\begin{array}{l}\text { Item } \\
\text { No. }\end{array}$ & Perceived Stress & WM & SD & VR & VI \\
\hline 2. & I miss my parents. & 3.51 & .7233 & $\begin{array}{l}\text { Strongly } \\
\text { Agree }\end{array}$ & Very High \\
\hline 3. & I miss my family members. & 3.44 & .7880 & Agree & High \\
\hline 1. & I miss my friends from high school. & 3.40 & .7390 & Agree & High \\
\hline 4. & I felt like I want to go back home. & 3.08 & .9843 & Agree & High \\
\hline 13 & $\begin{array}{l}\text { I'm worried about how I'll perform } \\
\text { academically. }\end{array}$ & 2.91 & .9477 & Agree & High \\
\hline 19 & $\begin{array}{l}\text { I feel exhausted from my academic } \\
\text { responsibilities. }\end{array}$ & 2.57 & .9073 & Agree & High \\
\hline 8 & I like being away from my parents. & 2.55 & .9455 & Agree & High \\
\hline 18 & $\begin{array}{l}\text { I'm worried about being in college in } \\
\text { general. }\end{array}$ & 2.37 & .9731 & Disagree & Low \\
\hline 14 & $\begin{array}{l}\text { It's hard for me to get along with new } \\
\text { people. }\end{array}$ & 2.35 & 1.005 & Disagree & Low \\
\hline 17 & $\begin{array}{l}\text { Since coming to college, I have } \\
\text { difficulty sleeping. }\end{array}$ & 2.33 & 1.0585 & Disagree & Low \\
\hline 9 & I feel lonely at school. & 2.29 & .9945 & Disagree & Low \\
\hline 10 & $\begin{array}{l}\text { Since starting my first year, I feel } \\
\text { depressed about being in college. }\end{array}$ & 2.25 & .9848 & Disagree & Low \\
\hline 15 & I'm easily irritated by my peers. & 2.19 & .8663 & Disagree & Low \\
\hline 12 & $\begin{array}{l}\text { I feel like my absences have } \\
\text { increased since I got to college. }\end{array}$ & 2.03 & 1.0246 & Disagree & Low \\
\hline 5 & I don't like my course. & 1.89 & 1.0151 & Disagree & Low \\
\hline 16 & I think about dropping out. & 1.61 & .9123 & Disagree & Low \\
\hline \multicolumn{2}{|r|}{ Overall Transition Shock Level } & 2.55 & .5230 & Agree & High \\
\hline
\end{tabular}

Legend: $1.00-1.49=$ strongly disagree $; 1.50-2.49=$ disagree $; 2.50-3.49=$ agree $; 3.50-4.00=$ strongly agree WM-Weighted Mean; SD-Standard Deviation; VR: Verbal Response; VI-Verbal Interpretation

The respondents perceived that they are experiencing transition shock. They strongly feel a sense of separation from their parents and miss their other family members and friends.

The research understands the college freshman experience as an identifiable period of transition. Students need to make their adjustments and to be supported by people and systems surrounded by them. According to Tinto, as cited in Brooman and Darwent(2013), students need to negotiate three separate stages: separation, transition, and incorporation. 
Conley, travers, and Bryant (2013) discusses that college students often report loneliness, homesickness, and distress with interpersonal relationships, which is expected considering the respondents live in the dormitories and are away from home. The results showed that the students have not fully adjusted to their living situation and have not formed new friends due to still missing their old high-school friends. Adjusting to a new environment is never easy and may take time getting used to. Coming into college, students may seem to have a grasp on the "needed" tools and necessities to get by in the college setting. They bring habits they had developed in high-school, thinking it is "good enough" but when they are thrust into the college setting, everything is chaotic and they are not able to cope with the requirements of their college lives (Hirsch, 2010).

\section{Relationship Between Emotional Intelligence and Stress Among the Respondents}

As shown in Table 7 , the $p$-value $(p=0.000)$ indicates that the relationship between emotional intelligence and stress is significant. Result also showed that there is a moderate negative relationship between emotional intelligence and stress $(R=-0.476)$. This means that the higher the Emotional Intelligence, the lower the stress that the respondents experience. Also, it is interpreted that about $23 \%$ of the variance in stress can be explained by Emotional Intelligence $\left(r^{2}=22.66\right)$. Thus, based on the statistical result, the null hypothesis stating that there is no significant relationship between emotional intelligence and stress is rejected.

\section{Table 7. Relationship between Emotional Intelligence and Stress among the Respondents}

\begin{tabular}{ccccc}
\hline Indicator & Computed $\boldsymbol{r}$ & \multicolumn{2}{c}{ Emotional Intelligence } \\
& $\begin{array}{c}\text { Qualitative } \\
\text { Description }\end{array}$ & $\boldsymbol{p}$-Value & Remark \\
\hline Perceived Stress & -.476 & Moderate & 0.000 & Significant \\
& & Negative \\
& Relationship & \\
\hline
\end{tabular}

Legend: +1 Perfect Relationship, +0.91-+0.99 Very High Relationship, +0.71-+0.90 High Relationship, +0.41+0.70 Moderate Relationship, +0.21-+0.40 Low Relationship, +0.01-+0.20 Negligible Relationship, O No Relationship Significant at $P<0.05$

The findings of the study are congruent with the studies done by Bowen et al. (2016). The study investigated the relationship between emotional demands, emotional intelligence, and perceived stress among the academic employees. The result revealed the inverted relationship between them, which means as emotional intelligence increases, the perceived stress scale reduces. 
In addition, the findings of the study are also in agreement with another study conducted by Kauts (2016). This study on the relationship between emotional intelligence and academic stress among 300 college students have shown that the students with high EI experienced lower academic stress, while the students with low EI reported high academic stress.

However, the findings of Kermani, Khoshbakht, Miri, and Moodi (2013) disagree with the results of the study. They conducted a cross-sectional study on students from four different faculties of medical sciences. The results of their study revealed that there was no significant correlation between EI scores and educational stress in students.

Relationship Between Emotional Intelligence and Transition Shock Among the Respondents According to Table 8, the relationship between emotional intelligence and transition shock is significant, having a $p$-value of 0.000 . It also reveals the moderate negative relationship between emotional intelligence and transition shock with the $r$-value of -.417. Hence, based on the statistical result, the null hypothesis stating that there is no significant relationship between emotional intelligence and transition shock is denied.

Table 8. Relationship Between Emotional Intelligence and Transition Shock Among the Respondents

\begin{tabular}{ccccc}
\hline Indicator & Computed $\boldsymbol{r}$ & \multicolumn{2}{c}{ Emotional Intelligence } \\
& $\begin{array}{c}\text { Qualitative } \\
\text { Description }\end{array}$ & $\boldsymbol{p}$-Value \\
Transition Shock & -.417 & $\begin{array}{l}\text { Moderate } \\
\text { Negative } \\
\text { Relationship }\end{array}$ & Remark \\
\hline & & 0.000 & Significant \\
\hline
\end{tabular}

Legend: +1 Perfect Relationship, $+0.91-+0.99$ Very High Relationship, $+0.71-+0.90$ High Relationship, $+0.41-$ +0.70 Moderate Relationship, +0.21-+0.40 Low Relationship, $+0.01-+0.20$ Negligible Relationship, 0 No Relationship Significant at $P<0.05$

It is an agreement to Parker, Summerfeldt, Hogan and Majeski (2004), who have conducted a study on the relationship between transition from high school to university and emotional intelligence among college freshman. The participants were all graduated high school within past 2 years. In order to measure the successful transition, they compared the high school grade-point-average (GPA) with the University GPA. The result showed that overall emotional intelligence scores was found to be poor predictors of academic success.

On the other hand, Parker et al.(2004) found that interpersonal, adaptability, and stress management abilities, which are included in emotional intelligence, seem to be important factors in successful transition from high school to university. 


\section{CONCLUSION}

Based on the results, the first-year students have an agreeable perception of well-being, selfcontrol, emotionality, and sociability. Moreover, their EI level appeared to be high. The firstyear students perceive high stress in their daily life. Also, they agree that they have a hard time transitioning from high school to college, as their level of transition shock is also high. The following are the recommendations based on the findings of the study:

1. An emotional intelligence test can be conducted prior to the start of the semester to gauge the student. A test to measure stress level and transition shock level should be conducted to see how well the student acclimates to the new academic environment.

2. It is recommended that first-year nursing students become aware of their emotional intelligence. And one should emphasize on developing emotional intelligence to manage stress and transition shock at college to get success in their academic endeavors.

3. Therefore, it is suggested that an intervention program be provided to increase the students' overall emotional intelligence.

4. Nursing educators should become aware of the emotional intelligence of incoming first-year nursing students. By knowing how high or how low the students' emotional intelligence is, the nursing educators can factor this with the students' overall performance, and perhaps the nursing educators may be more flexible with their requirements.

5. It is recommended to emphasize stress management among the first-year students. A psychological intervention should be given to the students to lessen their stress level.

6. Also, the nursing educators should provide activities that can promote first-year students' transition into the new academic environment, if their transition shock level is found to be high.

7. Future research on the long-term effect of emotional intelligence may also be conducted to assess the extent of stress and transition shock in all levels, not just firstyear students. Thus, one might expect the extent of stress and the extent of transition shock to change over the course of the student's college life. Students who have stayed in the university are likely to have a different extent of stress and transition shock at the end of their program when compared to levels at the start of their program, knowing that they have already adjusted to college life. Additional research 
may also be investigated with the indicators for emotional intelligence namely: wellbeing, self-control, emotionality, and sociability. Lastly, the researchers recommend future studies on the topic of emotional intelligence, stress, or transition shock to be conducted using a larger sample size.

\section{REFERENCES}

Andrei, F., Smith, M. M., Surcinelli, P., Baldaro, B., \& Saklofske, D. H. (2016). The Trait Emotional Intelligence Questionnaire. Measurement and Evaluation in Counseling and Development,49(1), 34-45.

Bhujade, V. M. (2017). Depression, anxiety and academic stress among college students: A brief review. Indian Journal of Health and Wellbeing,8(7), 748-751.

Bowen, P., Pilkington, A., \& Rose, R. (2016). The Relationship between Emotional Intelligence and Well-Being in Academic Employees. International Journal of Social Science Studies,4(5).

Brooman, S., \& Darwent, S. (2013). Measuring the Beginning: A quantitative study of the transition to higher education. Studies in Higher Education, 29(9), 1523-1541.

Conley, C. S., Travers, L. V., \& Bryant, F. B. (2013). Promoting Psychosocial Adjustment and Stress Management in First-Year College Students: The Benefits of Engagement in a Psychosocial Wellness Seminar. Journal of American College Health,61(2), 75-86.

Hirsch, D. (2010). The High School to College Transition: Minding the Gap. The New England Journal of Higher Education. Retrieved from http://www.nebhe.org/thejournal/the-highschool-to-college-transition-minding-the-gap/

Holinka, C. (2015). Stress, Emotional Intelligence, and Life Satisfaction in College Students. College Student Journal Southern Connecticut State University, 49(2), 300-311.

Jed Foundation. (2017, April 18). Students Who Feel Emotionally Unprepared for College More Likely to Report Poor Academic Performance and Negative College Experience. Retrieved from https://www.jebfoundation.org/first-year-college-experience-release/

Kauts, D. S. (2016). Emotional Intelligence and Academic Stress among College Students. An International Journal of Education and Applied Social Sciences,7(3), 149-157.

Kermani, T., Khoshbakht, H., Miri, M., \& Moodi, M. (2013). The relationship between emotional intelligence and academic stress in students of medical sciences. Journal of Education and Health Promotion, 2(1), 40.

University of Tasmania. (2014). Transition shock, work-readiness and the initial stages of role adaptation for newly graduated registered nurses. Retrieved from https:// blogs.utas.edu.au/snm-pep/2014/05/06/transition-shock-wor-readiness-and-the-initial-stagesof-role-adaptation-for-newly-graduated-registered-nurses/

Nakalema, G., \& Ssenyonga, J. (2014). Academic Stress: Its Causes And Results At A Ugandan University. African Journal of Teacher Education, 3(3). 
National Alliance on Mental Health. (2012). A SURVEY REPORT ON MENTAL HEALTH. Retrieved from https://www.nami.org/About-NAMI/Publications-Reports/SurveyReports/College-Students-Speak_A-Survey-Report-on-Mental-H.pdf

Orion, H., Forosuelo, E., \& Cavalida, J. (2014). Factors Affecting Student's Decision to Drop Out of School. SLONGAN, 2, 1-16.

Watson, J. C., \& Watson, A. A. (2016). Coping Self-Efficacy and Academic Stress Among Hispanic First-Year College Students: The Moderating Role of Emotional Intelligence. Journal of College Counseling, 19(3), 218-230. 